\title{
Ethnologies
}

\section{Les objets sont des lieux de savoir}

\section{Élisabeth Kaine}

Volume 24, numéro 2, 2002

Musées

Museums

URI : https://id.erudit.org/iderudit/006645ar

DOI : https://doi.org/10.7202/006645ar

Aller au sommaire du numéro

Éditeur(s)

Association Canadienne d'Ethnologie et de Folklore

ISSN

1481-5974 (imprimé)

1708-0401 (numérique)

Découvrir la revue

Citer cet article

Kaine, É. (2002). Les objets sont des lieux de savoir. Ethnologies, 24(2), 175-190. https://doi.org/10.7202/006645ar

\section{Résumé de l'article}

Voici quelques questions posées par une professeure en design, en regard de la valeur des pratiques de design traditionnelles autochtones à des fins d'enseignement de cette discipline ainsi que des réponses formulées à travers des expériences concrètes d'élaboration de méthodes et d'outils. Ces recherches appliquées ont permis de développer une banque de données interactive permettant une compréhension systémique des objets de design. Quelques projets de design réalisés dans le cadre des ateliers Design et culture matérielle sont présentés comme ébauches de réponses aux questions posées.
Ce document est protégé par la loi sur le droit d'auteur. L'utilisation des services d'Érudit (y compris la reproduction) est assujettie à sa politique d'utilisation que vous pouvez consulter en ligne.

https://apropos.erudit.org/fr/usagers/politique-dutilisation/ 


\title{
LES OBJETS SONT DES LIEUX DE SAVOIR ${ }^{1}$
}

\author{
Élisabeth Kaine \\ Département des arts et lettres \\ Université du Québec à Chicoutimi
}

Je suis professeure en design et c'est d'abord l'attrait pour les objets qui motive mes recherches. Mais cet attrait est aussi relié à l'identité ; non pas à la recherche de celle-ci, mais plutôt à la mise en relation de différentes identités. Je suis métisse, de père irlandais et de mère wendate. Les objets prennent pour moi un sens particulier, comme s'ils me permettaient de toucher, pour mieux le saisir, cet Autre qui réside à la fois ailleurs et en moi. Les objets m'ont aidée à gérer la difficile position de l'entre-deux et à la considérer comme une force de transmission entre mes deux mondes.

Le projet Design et culture matérielle a débuté officiellement en 1992 par l'obtention d'une subvention de recherche du Réseau des Universités du Québec, obtenue en collaboration avec Céline Poisson, professeure en design à l'université du Québec à Montréal, et Pierre-André Vézina, designer professionnel. Mais ses racines remontent à beaucoup plus loin, car dès l'enfance passée sur la réserve de Wendake, il y avait l'attrait d'une petite fille métisse pour les indiens qui, originaires de la Côte nord et de la Basse côte nord, résidaient à l'occasion au village Huron. Leur présence fut un puissant pôle d'attraction qui donna naissance à un projet d'adolescence qui consistait à refaire le chemin des objets traditionnels indiens, à la manière de l'archéologie expérimentale, depuis la cueillette de la matière première jusqu'à l'objet fini, expérience vécue en forêt (1971).

1. Cet article a fait l'objet d'une communication au colloque du Célat, Le Soi et l'Autre, au Musée de la civilisation, le 18 février 2002. 


\section{D'abord apprendre, pour pouvoir ensuite enseigner}

Si j'ai d'abord voulu apprendre à faire des objets selon les méthodes traditionnelles autochtones, j'ai vite voulu apprendre autre chose que les techniques et ce sont les objets existants, conservés en musée, qui, à mon sens, étaient les meilleurs vecteurs des savoirs qui m'intéressaient. La première motivation du projet Design et culture matérielle fut donc la soif d'apprendre au moyen des objets d'appartenance autochtone. Apprendre pour mieux accomplir mon travail de designer qui, acquis à l'école du modernisme, me semblait vain, enfantin dans sa recherche constante de la nouveauté et terriblement prétentieux face à des milliers d'années de pratique de design précédant la révolution industrielle. J'ai tenté de développer des approches, des méthodes et des outils d'interprétation et de transmission des savoirs contenus dans les objets, que je comprends comme étant les catalyseurs de la pensée des Hommes ; et d'utiliser ces façons de voir et de faire pour la formation de mes étudiants. L'objectif pédagogique motivant le recours aux pratiques de design des peuples autochtones est d'amener les futurs designers à une ouverture vers l'Autre, à sortir de l'approche extrêmement égocentrique et ethnocentrique du design moderniste, à nourrir leur culture du design. Le corpus de cette expérience comprend trois cours: Introduction aux théories du design, Histoire du design et Design de l'objet. Plusieurs étudiants poursuivent des recherches entreprises lors de leur passage au projet Design et culture matérielle dans le cadre de la maîtrise.

Ce projet fonctionna dès le départ selon la méthode des conduites à projets, méthodes largement utilisées par les créateurs en design. Un parcours organique, vivant, en continuelle transformation, qui n'a jamais été figé dans un plan ou dans l'attente de résultats prouvant une hypothèse. Le projet a plutôt créé son propre trajet, s'est auto-construit et mon désir est toujours le même : que cette quête de vouloir comprendre et rendre visible l'Autre à travers la matière qu'Il a façonnée reste mouvante, qu'elle me surprenne et m'indique la voie à suivre.

\section{Des questions}

À la question formulée par une designer : «comment réactiver les objets du passé dans une pratique contemporaine ?", s'est rattachée toute une chaîne de nouvelles interrogations auxquelles j'ai tenté d'apporter des réponses par différentes interventions. 
Comment trouver d'autres voies que celle tracée par le design moderniste ?

J'ai voulu aller voir et toucher les objets du passé mais aussi ceux issus d'une philosophie du design diamétralement opposée à celle des modernes. Je voulais aussi sortir de l'approche purement formaliste des années 1980 et amener mes étudiants à se "frotter » à d'autres philosophies du design, pour sécréter autre chose. Les pratiques de design des peuples autochtones, indiens et inuit, représentaient à mon sens la parfaite antithèse de celles appliquées dans les sociétés de consommation. J'ai d'abord voulu constituer un répertoire personnel des chefs-d'œuvre de design produits par ces peuples. Avec Pierre-André Vézina, également designer, nous avons travaillé avec les conservateurs des collections autochtones du musée de la Civilisation, du musée des Civilisations, du musée McCord d'histoire canadienne et du Laboratoire d'archéologie de l'Université du Québec à Chicoutimi. Nous avons regardé, en réserve ou sur fichiers papier ou informatique, tous les objets des collections et avons choisi de façon très intuitive au-delà de cinq cents objets. Puis ce sont ces derniers qui nous ont en quelque sorte dicté une grille. Nous les regardions, ébahis, et les questions fusaient. Ce sont ces questions qui devinrent signifiantes de ce qu'il était pertinent de connaître. Une deuxième sélection a été réalisée à partir de cette grille dictée par les premiers objets choisis, pour ainsi constituer une banque d'objets porteurs d'enseignements de diverse nature pour la pratique contemporaine du design.

Comment rendre visibles ces objets de musée, ces chefs d'oeuvre maintenus pour la plupart hors de notre regard?

Après avoir côtoyé tous ces chefs-d'oeuvre, les regarder sur photocopies n'avait aucun intérêt, surtout pour de futurs spécialistes de la forme. Ils étaient devenus vides. De plus, il était impossible de pouvoir enseigner quoi que ce soit avec le peu d'informations disponibles dans les banques de données des musées.

Trois années de recherche, de conception et de programmation furent consacrées à la réalisation d'un petit musée virtuel dont l'ambitieux projet est de rendre actifs les savoirs contenus dans les objets. Il s'agit en fait d'une banque de données interactive servant à la fois des objectifs scientifiques (catalogage, description, analyse, comparaison) et artistiques (compréhension globale, évaluation qualitative, expression, expérience générée). Deux cents items d'information composent le regard à multiples facettes posé sur l'objet et son système. 
Les artefacts sont répertoriés sous quatre fonctions : «se nourrir », « contenir et transporter », « retirer de la matière », «se vêtir ».

L'interface n'est pas terminée faute de financement, mais l'outil est utilisé de façon satisfaisante comme lieu d'archivage, d'analyse, d'acquisition de connaissances, d'inspiration lors des ateliers et comme outil de diffusion lors des expositions. La banque de données interactive est un lieu vivant puisque toutes les nouvelles créations sont programmées, constituant une sorte de lignée généalogique des objets. Il s'agit donc d'un musée portatif mais aussi d'une galerie d'art contemporain, tous deux très utiles pour la tenue des ateliers Design et culture matérielle qui souvent ont lieu en régions éloignées des grands centres. Le contenu est à la fois descriptif et expressif de la culture matérielle passée et contemporaine et permet la comparaison, par la possibilité de réaliser des appels de recherche, de ces différents moments de l'histoire des objets.

Comment faire en sorte que ces chefs-d'oeuvre soient véritablement compris au-delà de la seule perception de la forme et potentiellement "imprégnables " dans l'imaginaire de jeunes designers? Comment utiliser ces objets pour l'enseignement du design et comme stimulants pour la création ?

Après avoir répertorié, présenté et décrit les objets, il fallait en extraire les savoirs, les rendre actifs comme vecteurs de connaissances. La seule description était insuffisante pour véritablement rendre «saisissables» ces savoirs. L'outil devait permettre d'évaluer qualitativement et quantitativement, de saisir non seulement l'entité « objet » mais également les relations au monde et à l'individu qu'il génère et/ou desquelles il découle.

Le recours à plusieurs champs de savoirs était ici indispensable, l'histoire du design se confinant à l'histoire des objets postérieurs à la révolution industrielle et l'histoire de l'art étant omnubilée par l'histoire du beau. Je refuse de classer les objets selon les seuls critères technologiques ou esthétiques et, en ce sens, ce projet est beaucoup plus près de l'anthropologie pour qui tout objet est potentiellement signifiant. Par une approche phénoménologique, le projet Design et culture matérielle tente de partir de l'objet, médiateur, et de remonter vers les connaissances qu'il véhicule. Il s'agit d'une approche antiévolutionniste puisque je ne crois pas que les objets actuels soient supérieurs aux objets anciens. Ils appartiennent à différents paradigmes et pour que la comparaison soit signifiante, ces derniers doivent être pris en compte. 


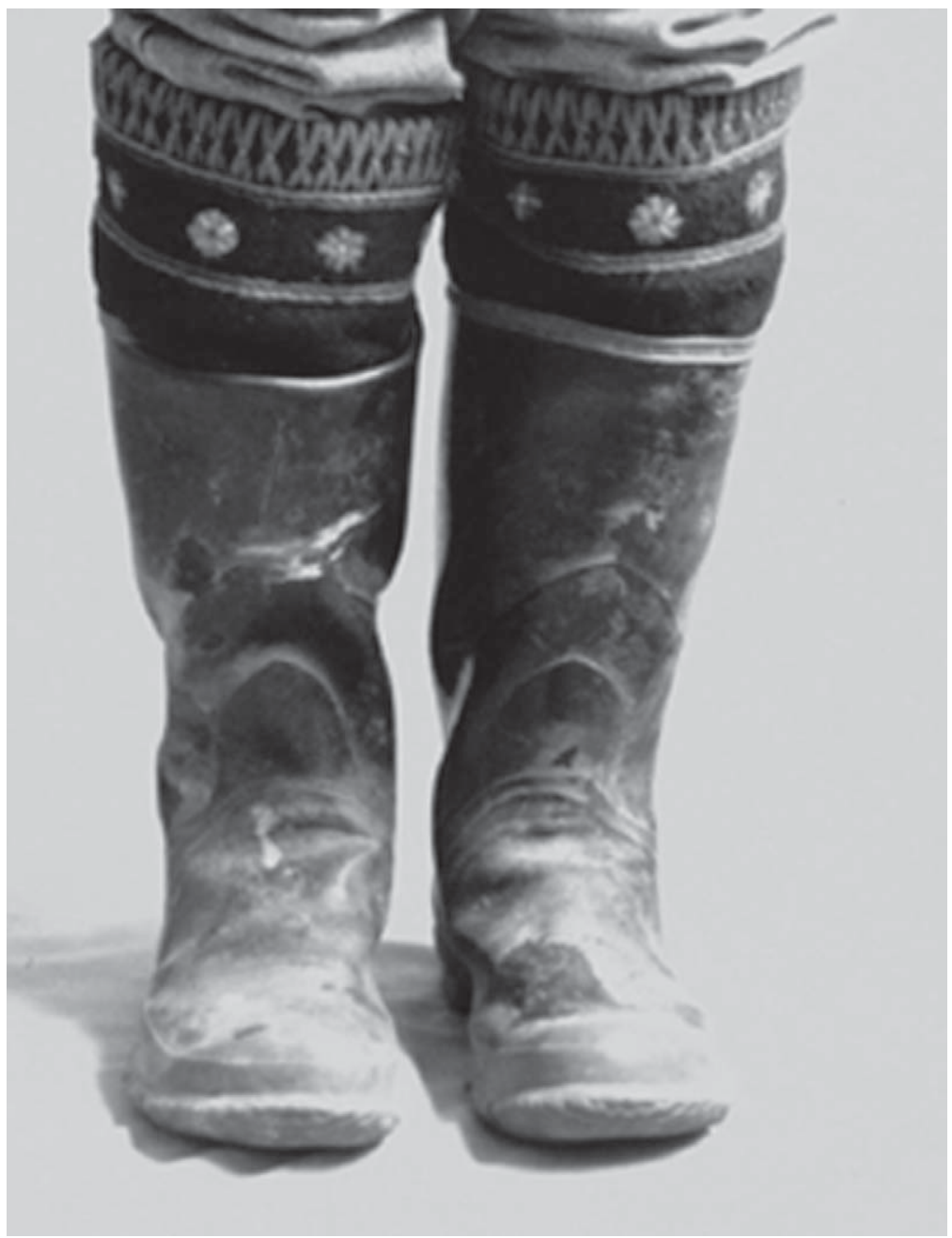

Figure 1. Bottes de caoutchouc avec doublure en laine foulée, objet \# 161, banque de données Design et Culture matérielle. Ces bottes perpétuent l'utilisation du principe des multicouches, inventé par les inuit, mais utilisent des objets industriels et des matériaux étrangers à leur culture traditionnelle.

C'est pourquoi une section d'analyse sémiologique (perception) et une autre d'évaluation phénoménologique (expérience), permettent à l'utilisateur de littéralement entrer dans l'univers de l'objet. Ici l'interprétation n'est pas donnée, mais constituée à l'aide d'une série d'étapes, par l'utilisateur de la banque. Il s'agit d'un passage vers la création d'un nouvel objet, qui s'effectue d'abord par une appropriation cognitive et symbolique de l'objet d'étude. La possibilité qui est offerte 
à l'utilisateur d'interpréter, d'évaluer, de qualifier certains paramètres de son objet d'étude, permet une empreinte plus ancrée que la seule connaissance factuelle. C'est la complémentarité entre les données descriptives et les interprétations, les informations et les impressions, qui permet une saisie systémique de l'objet.

Comment éviter le recours systématique aux clichés formels associés à la culture autochtone? Comment transmettre l'idée que la culture n'est pas que traditionnelle?

Après deux applications de l'atelier Design et culture matérielle en classe, j'étais déçue de constater que les étudiants restaient collés à une approche formelle et passéiste de la culture autochtone. Les stéréotypes étaient largement utilisés et les matériaux choisis pour la mise en forme des concepts n'étaient jamais contemporains. Le logiciel, principal source d'informations et d'inspiration, ne présentait que des objets traditionnels, ce qui n'incitait pas les jeunes designers à changer leur idée préconçue de la culture matérielle autochtone : le tipi, le cuir, la fourrure, l'arc et la flèche... L'exercice était cependant concluant pour valoriser les pratiques de design des cultures traditionnelles autochtones et pour stimuler la comparaison avec un autre paradigme de l'histoire du design.

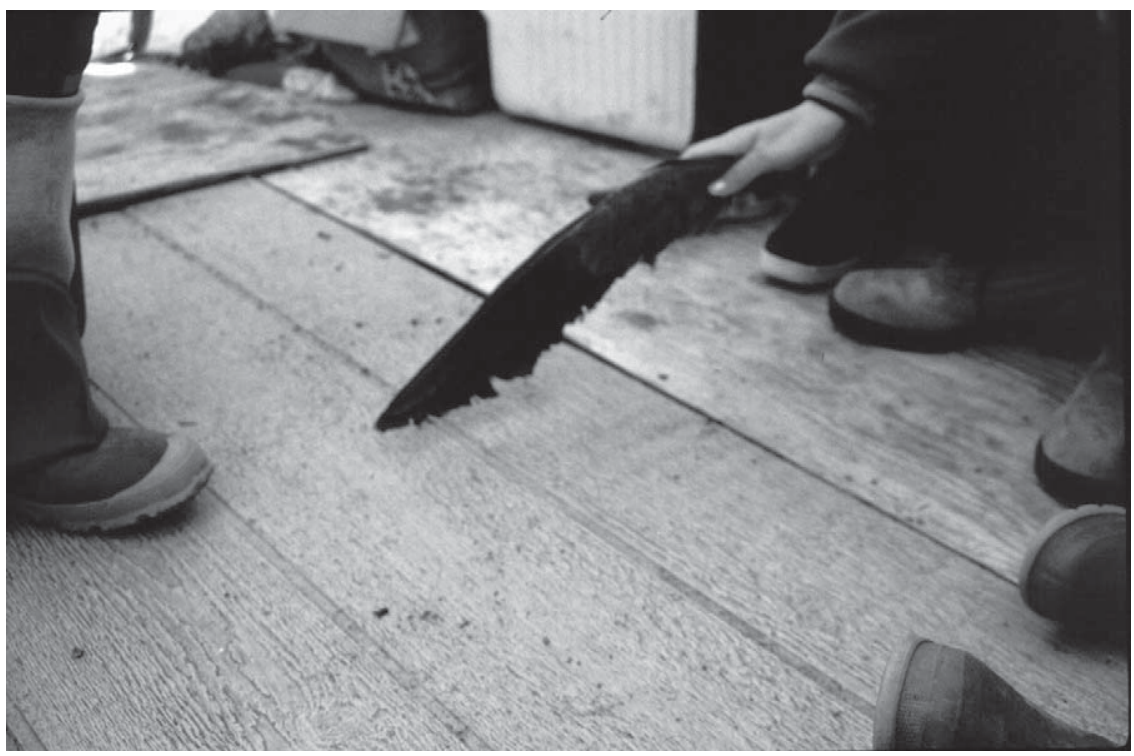

Figure 2. Aile d'oie utilisée pour nettoyer la tente. Inukjuaq, 1995. 
Le logiciel Design et culture matérielle n'opère aucune hiérarchie des objets, tous sont considérés comme étant potentiellement signifiants.

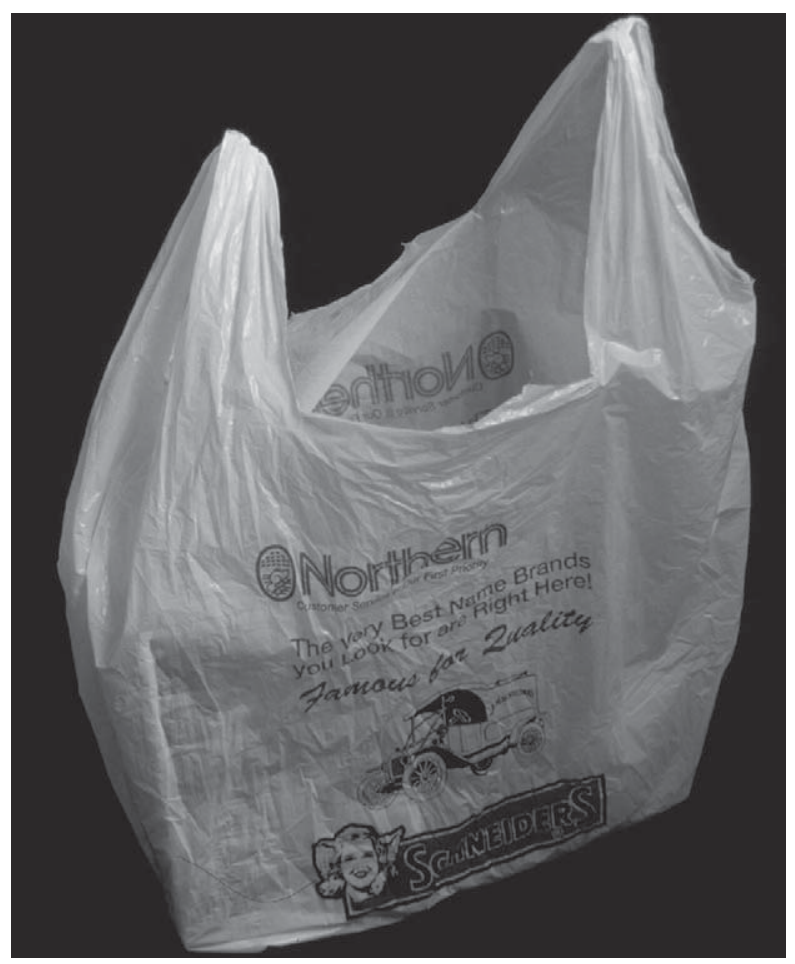

Figure 3. Sac Northern, objet 175, banque de données Design et Culture matérielle.

Oui, les Inuit utilisent des sacs de plastique...

Figure $4 \ldots$ ainsi que des fleurs de plastique.

Cimetière, Inukjuaq.

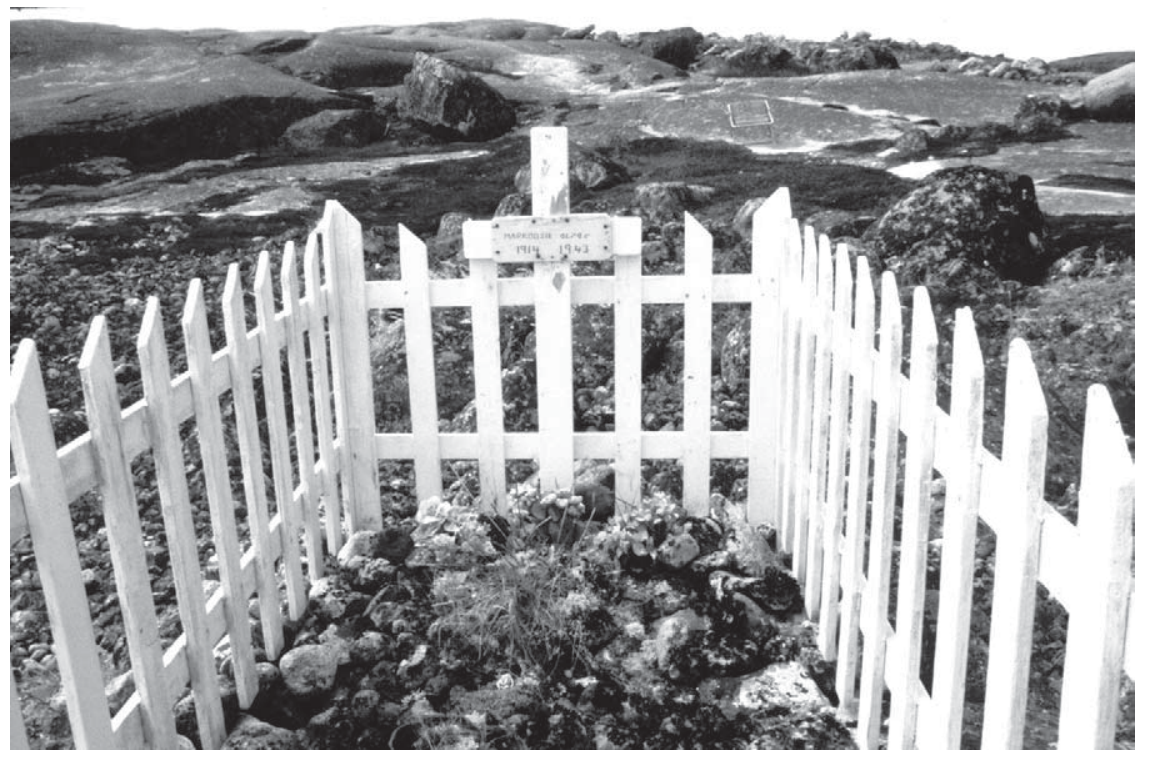


J'ai pensé qu'il fallait augmenter la banque de données de témoins actuels de la culture matérielle autochtone. En 1995, un séjour de trois semaines à Inukjuaq, au Nunavik, nous a permis de répertorier l'ensemble des objets de la famille Ruptash, utilisés par quatre personnes : le père euro-canadien (John Ruptash), la mère inuit (Sarah Naluktuk) et deux enfants inuit (Vanessa et Shawn). Cette étape de recherche a permis d'approfondir notre connaissance de la culture matérielle contemporaine, de manière à donner aux éventuels utilisateurs de la banque de données une vision réaliste et actuelle de la culture inuit, trop souvent valorisée par ses réalisations passées. De plus, le logiciel étant utilisé lors d'ateliers de création ayant lieu dans les communautés nordiques, il importe que les participants à ces ateliers puissent s'identifier au présent au contenu de la banque de données. Ces objets, qu'on pourrait qualifier "d'objets métissés », montrent une intégration remarquable de principes, de fonctions, de matériaux ou de modes d'emploi appartenant à différentes cultures. Ils témoignent de la culture inuit contemporaine.

Cette stratégie a permis d'établir une chronologie des objets, de voir les continuités et les discontinuités dans cette chronologie, de lire les intégrations interculturelles et les métissages de formes, de principes, de techniques ou de rituels d'utilisation inscrits dans les objets (figures $1,2,3,4)$.

Ce travail s'avéra très important pour toutes les clientèles qui ont suivi les ateliers par la suite. Les jeunes Inuit en particulier furent ravis de reconnaître des objets de leur quotidien dans le logiciel et cette reconnaissance a contribué à leur donner la confiance nécessaire à la création. De même, le public qui a visité les expositions en milieu nordique a eu beaucoup de plaisir à visionner ce contenu. Pour les étudiants de l'UQAC, cette partie de l'échantillonnage donnait une image actuelle et réaliste de la culture matérielle autochtone et permettait de comparer similitudes et dissemblances (passé/présent, autochtone/allochtone) entre les objets. Ce nouveau contenu a largement contribué à une meilleure connaissance de la culture autochtone et à la production d'objets libérés des stéréotypes, images figées et «figeantes" pour la création.

Ce projet n'est pas associable au style post-moderne ou néo en design. Apparue dans les années 1980, cette approche stylistique utilise un vocabulaire formel de l'architecture classique réinterprété 
essentiellement par deux stratégies : utiliser des éléments d'architecture décontextualisés pour la création de pièces de mobilier et jouer avec les échelles, le tout agrémenté de couleurs pastels. Ce ne sont pas uniquement les formes qu'il faut regarder comme inspirantes, mais également les qualités, les principes, les philosophies, les savoir-faire qui peuvent, de façon signifiante, s'implanter dans les pratiques de design actuelles. Une des grilles permet, par exemple, à l'étudiant d'évaluer puis de comparer «le degré de transparence de la technique » entre des objets ethnologiques et/ou contemporains qu'il aura choisis. L'acte de comparer amène les utilisateurs à prendre position en quantifiant et en qualifiant différents paramètres. En donnant une valeur, par la comparaison, l'utilisateur comprend les différents paradigmes et paramètres des pratiques de design d'objets : la fonction, le principe de fonctionnement, l'ornement, les rituels d'utilisation, etc. (Figure 5).

La comparaison avec une autre philosophie du design peut amener les designers à opérer une critique de la société de consommation dans laquelle ils évoluent. Pierre-André Vézina constate que nous sommes des paresseux, qui accomplissons des actions machinalement, omnubilés par l'image de l'efficacité des objets, qui n'est qu'un leurre. L'exemple

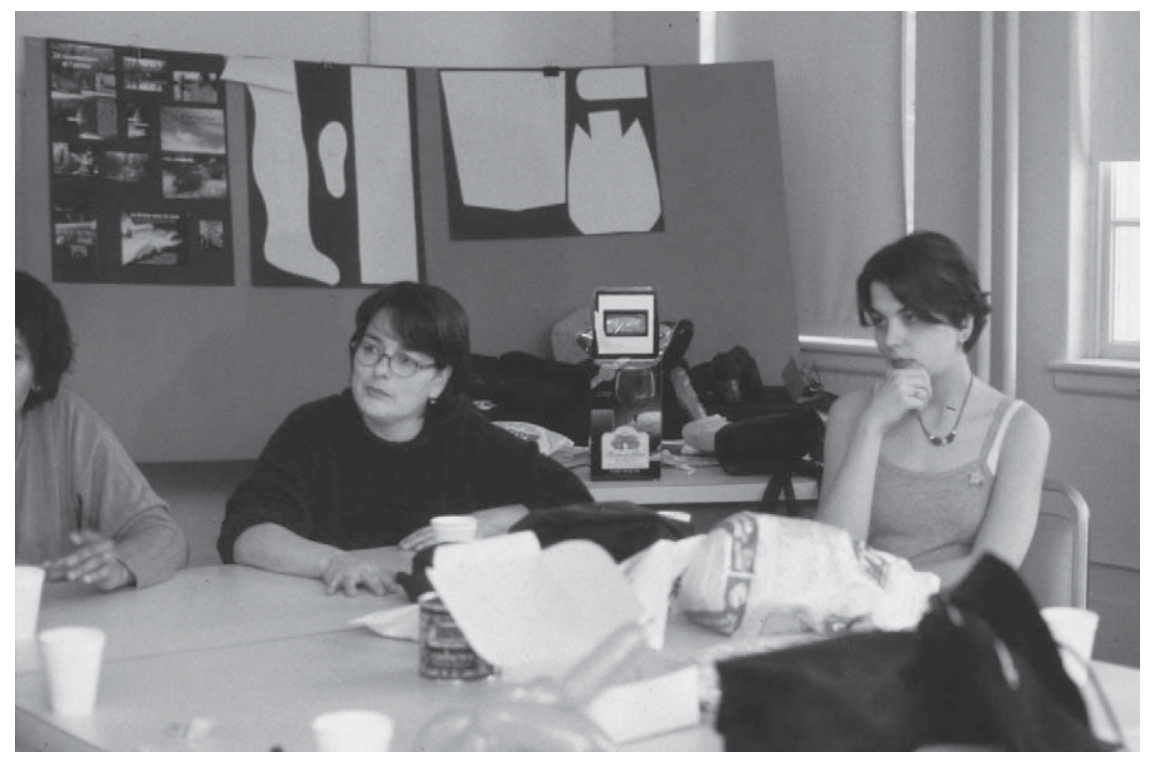

Figure 5. Josée Robertson de Mashteuiatsh et Isabelle Tremblay de Chicoutimi, étudiantes en design, discutent de leurs projets de design dans le cadre du cours Design de l'objet, sous la responsabilité de Denise Lavoie, co-chercheure, 1999. 
de la balayeuse pour ramasser les feuilles mortes est probant, puisque lorsqu'on analyse le scénario d'utilisation de cet objet, on constate qu'il permet l'économie d'un seul geste, se pencher. Il exige par contre entretien et entreposage. Le meuble de rangement de Pierre-André est en fait un manifeste contre ce type d'objets, puisqu'il demande un effort de la part de l'utilisateur qui doit soulever le poids des lattes de bois superposées pour accéder au contenu du meuble (figure 6).

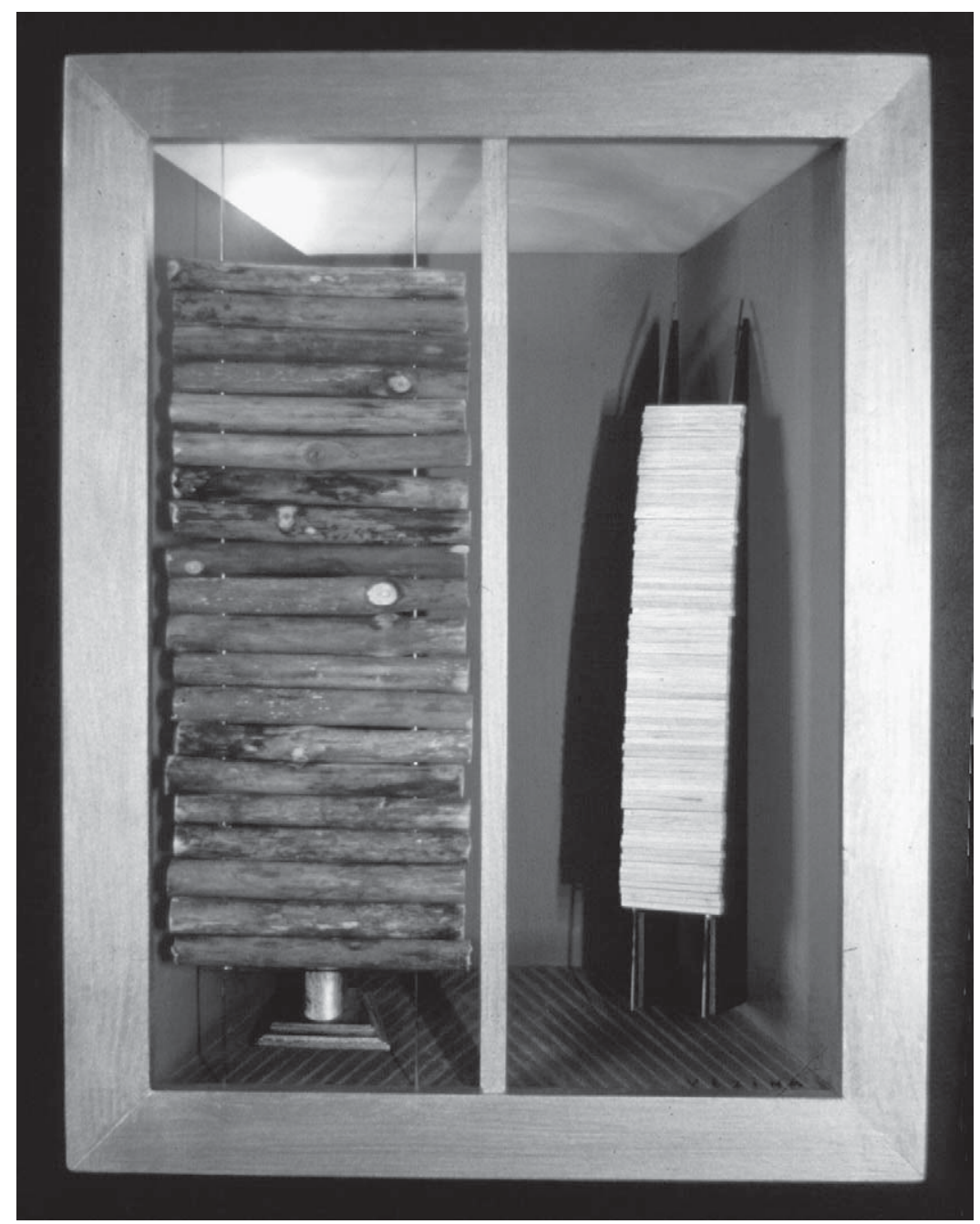

Figure 6. Meuble Soulever. Objet 221.

Meuble de rangement, Pierre-André Vézina.

Atelier Design et culture matérielle pour designers professionnels. 


\section{Des exemples d'objets-savoirs}

Le manteau inuit en peau d'intestin de baleine, une approche systémique de l'objet

À mon avis, ce manteau imperméable est le plus grand chef-d'oeuvre de l'histoire des objets. On prétend que son invention remonte à au moins cinq mille ans, bien avant l'invention des plastiques. L'inventivité est présente à tous les niveaux : techniques d'extraction et de traitement de la matière première, patron, points de couture, adéquation à la fonction, principe du multicouche (porté sur une fourrure, l'imperméable devient coupe-vent), beauté de l'objet, parfaite symbiose des facteurs fonctionnels et symboliques puisque ce manteau était également utilisé pour certains rituels, sa transparence étant associée au monde des esprits.

Le village Haïda : une architecture de relation plutôt que de démarcation

Le schéma d'intégration des villages au territoire des peuples de la côte ouest canadienne démontre bien une des forces de la culture matérielle autochtone qui intègre les mondes spirituel et matériel. Ces villages sont toujours construits devant la mer et à l'orée de la forêt, sur l'axe de rencontre de ces mondes. Le fonctionnalisme rationaliste a complètement évacué ces paramètres de la conception des artefacts et architectures, puisque seuls les facteurs fonctionnels et économiques sont pris en compte.

\section{Une ergonomie humaniste plutôt que machiniste}

Les outils, ustensiles et vêtements autochtones traditionnels offrent une relation corps/objet de qualité exceptionnelle, comme si ces objets étaient des extensions du corps. Les objets modernistes (industriels) n'ont jamais égalé le "fait main » en termes ergonomiques. La production informatisée et la robotisation nous permettront probablement sous peu d'atteindre ce haut niveau de qualité ergonomique par les possibilités de formes complexes qu'ils permettront. Il est donc pertinent d'étudier ces modèles.

Des objets, mais aussi des attitudes

Des façons de faire (les rituels accomplis par le biais de la fonction) et les valeurs de ce faire pour le peuple producteur (par le biais du 
symbole), sont intriquées aux objets. Les étudiants participant aux ateliers réussissent à lire ces paramètres et à les intégrer à leur création, ce qui leur permet d'opérer des changements d'attitude dans leur pratique du design en passant par trois niveaux d'apprentissage : 1) comprendre la valeur de l'objet en regard du contexte qui l'a vu naître, des rituels qu'il permet, de la façon dont il sert les Hommes ; 2) comparer à sa propre culture de consommation ; 3) exprimer l'expérience vécue par le biais de ce «frottement », car l'expression est un transmetteur de connaissances complémentaire à la description et à l'explication.

Mon intérêt, en tant que professeure, ne se situe pas au premier abord au niveau des objets mais bien au niveau des attitudes acquises. En première année la tendance est plus marquée pour les aspects visuels, formes et matériaux stéréotypés, mais une évolution rapide s'opère vers d'autres niveaux de sens. Les objets produits témoignent de points de vue critiques, de volontés d'opérer des changements ou de sensibiliser les utilisateurs, et d'un véritable respect des pratiques de design et de la culture autochtones. Je constate qu'ils apprennent à mettre leurs connaissances au service de l'Autre, à développer une approche moins égocentrique de la création, et s'inscrivent comme designers dans une longue lignée temporelle que leur époque avait refusé de considérer.

\section{Exemples d'objets créés dans le cadre des ateliers Design et culture matérielle}

Figure 7. Panier pour la cueillette des petits fruits et sac à dos pour ramener le précieux butin.

Objet 227, Julie Lavoie, 2ème année. Cours Design de l'objet, sous la responsabilité de Denise Lavoie, co-chercheure, 1997.
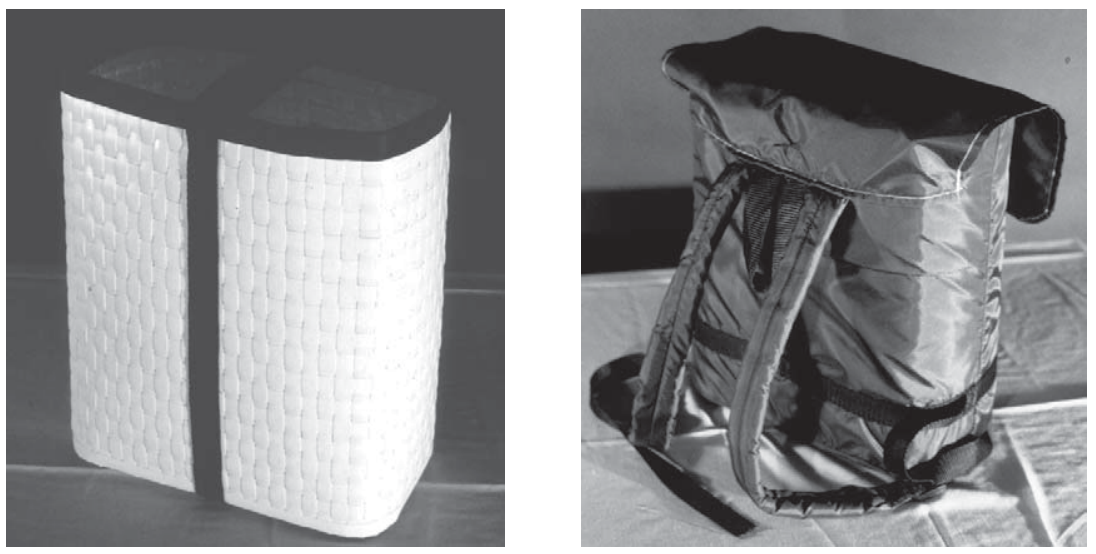


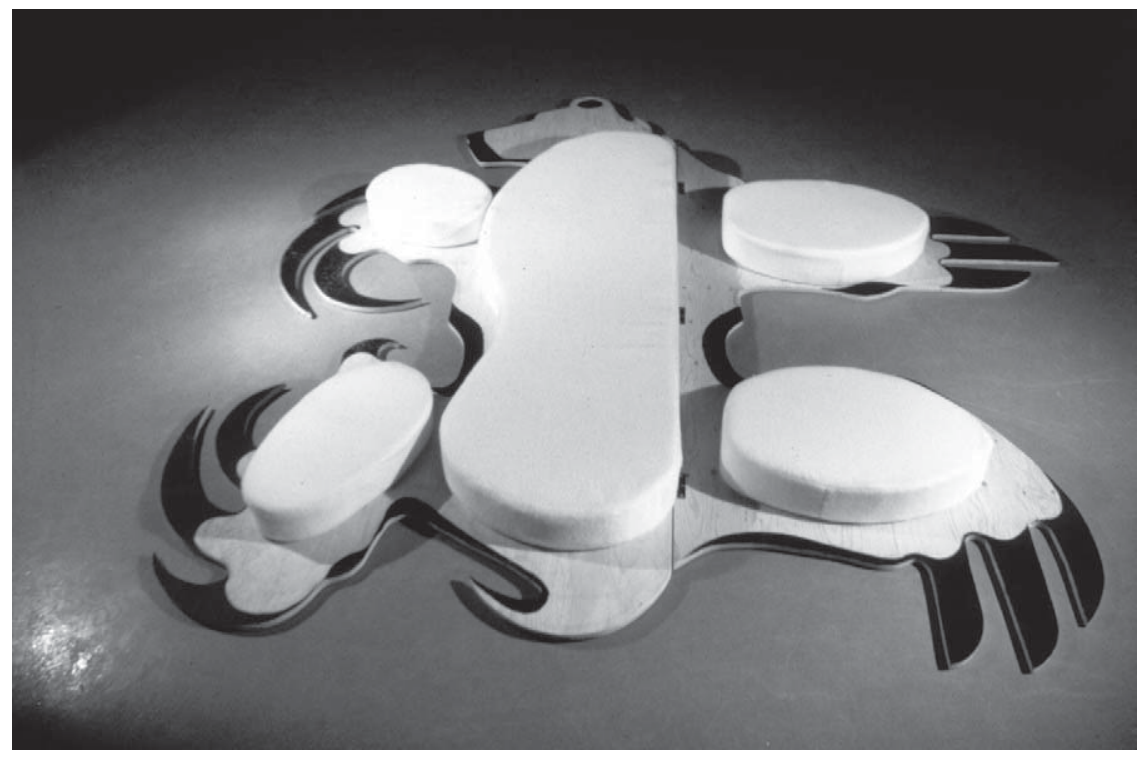

Figure 8. Fauteuil transformable. Ghyslain Perron, 1ère année. Cours Mobilier de création, sous la responsabilité de Pierre-André Vézina, 1995.

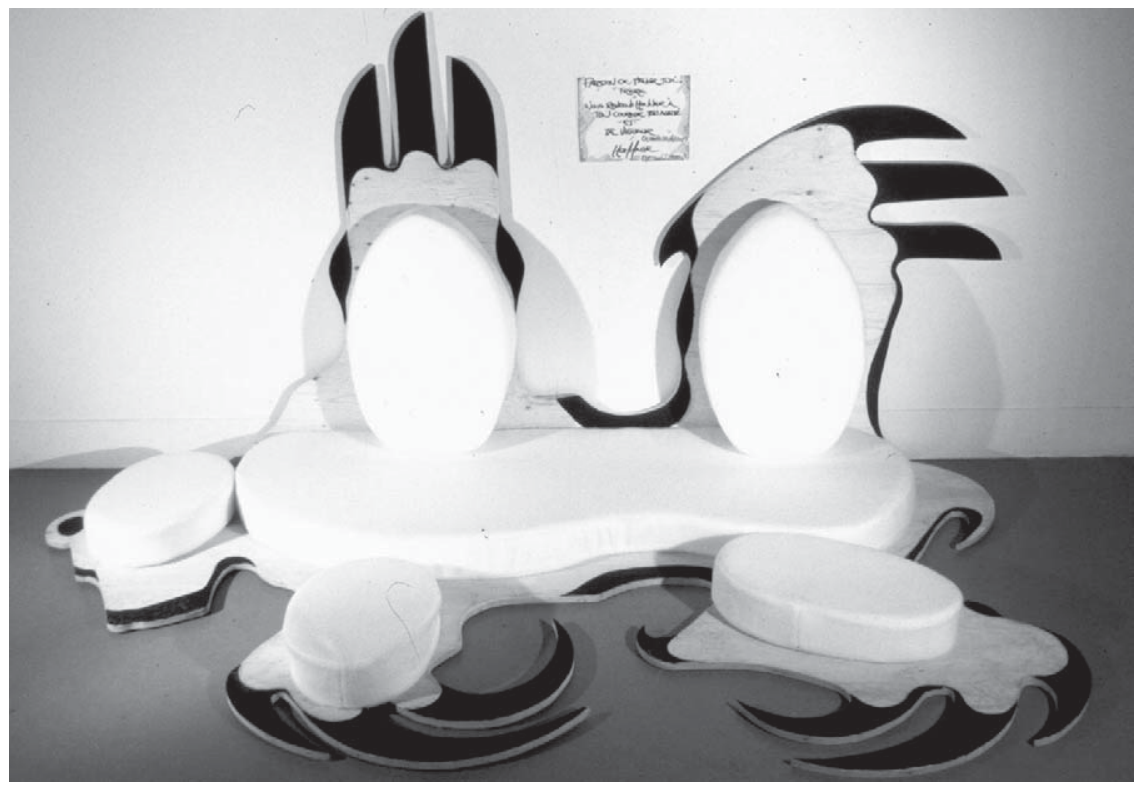


Figure 9. Chaise Arbre, Lise Bouchard, 1ère année.

Cours Mobilier de création, sous la responsabilité de Pierre-André Vézina, 1995.

Souvent, au cours de la première année, les objets demeurent des recherches formelles.

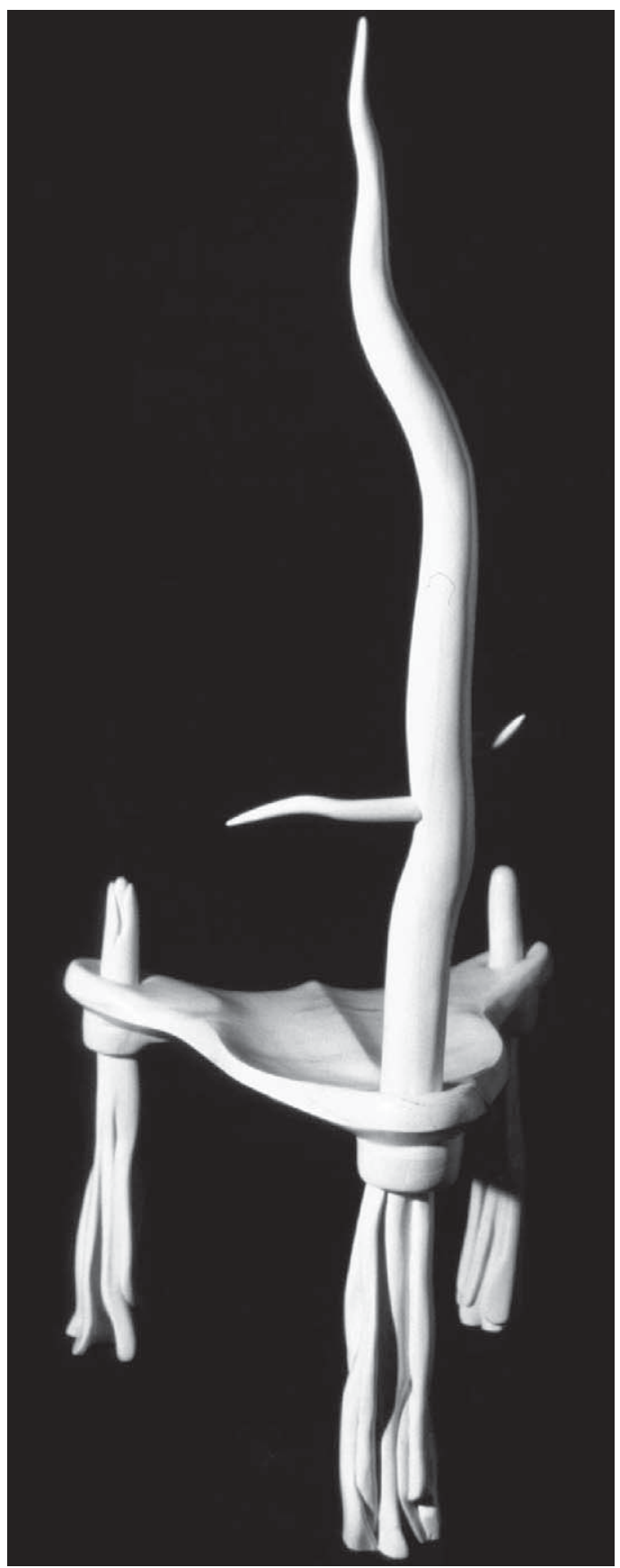




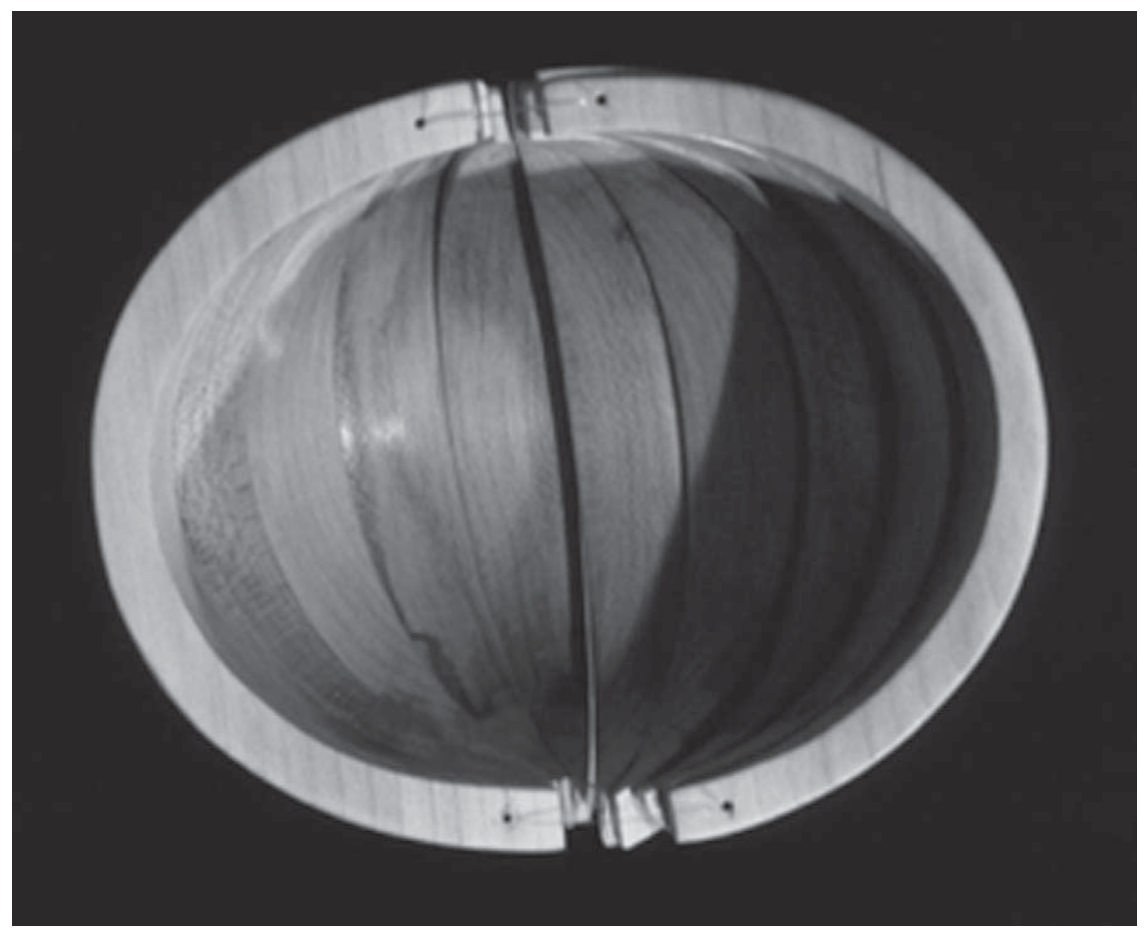

Figure 10. Bol pour boire à même la source, les mains jointes. Daniel Ménard, 2ème année. Cours Design de l'objet, sous la responsabilité de Denise Lavoie, 1998.

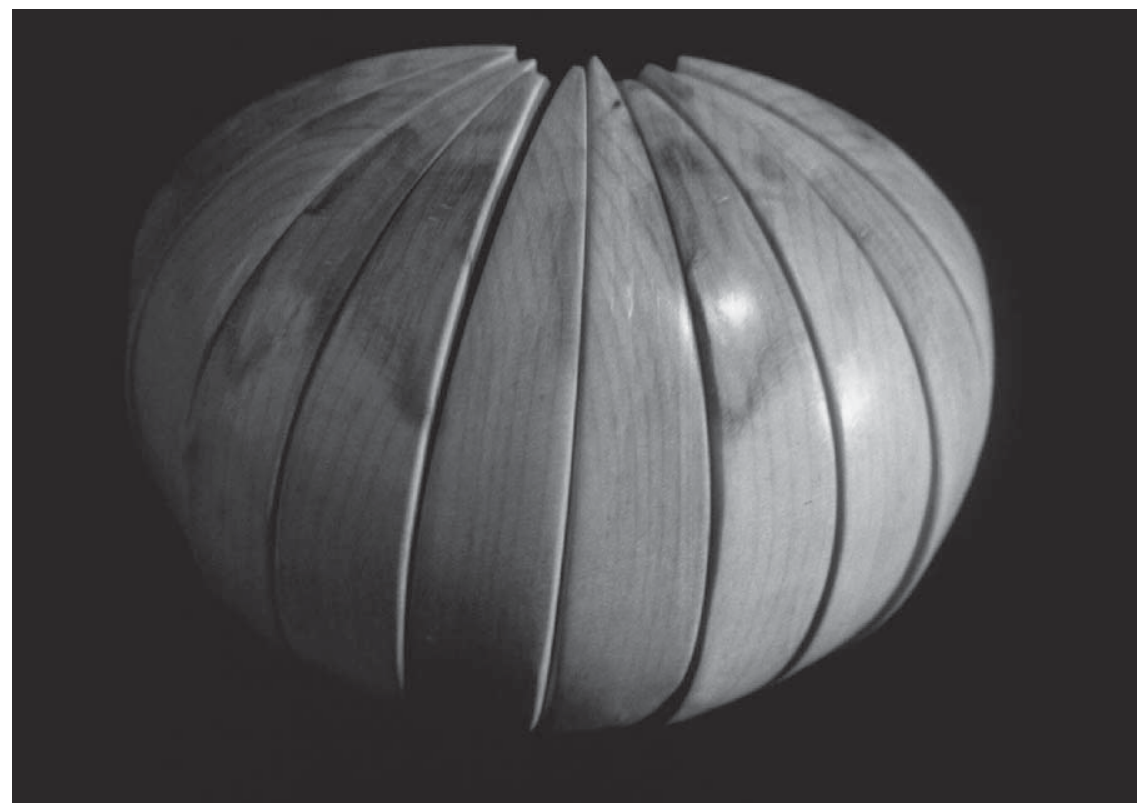


Figure 11. À gauche Atelier nomade de Pierre-André Vézina; à droite Bols d'offrande de Denise Lavoie, accompagnés des photographies de Robert Monderi et de Karim Rholem. Exposition Paysages, groupe Design et culture matérielle, Chicoutimi, 2000.

Ces objets furent réalisés dans le cadre de l'Atelier Design et culture matérielle pour designers professionnels, 1996.

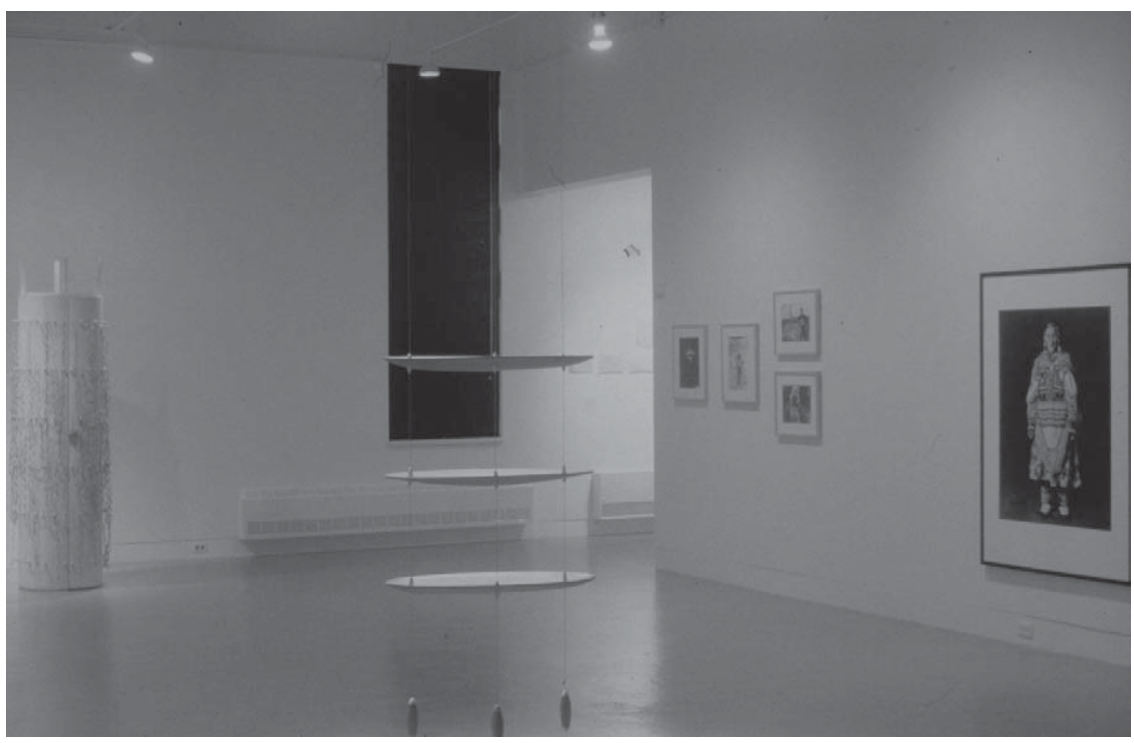

Le projet Design et culture matérielle oeuvre

- au développement d'une approche et de méthodes pédagogiques pour l'enseignement du design au niveau universitaire (UQAC) arrimées à la culture autochtone ;

- au développement d'ateliers de création en design pour les jeunes autochtones des écoles primaires, pour tenter de leur permettre de créer au présent, tout en intégrant le riche passé de la culture matérielle autochtone ;

- au développement d'ateliers de création en design pour les jeunes allochtones des écoles primaires, pour tenter de changer les perceptions vis à vis des cultures autochtones ;

- à la mise sur pied d'une collaboration entre designers autochtones et designers allochtones dans le but d'enrichir les visions et pratiques de chacun. 